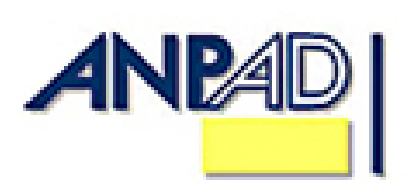

Disponível em

http://www.anpad.org.br/rac

RAC, Curitiba, v. 14, n. 5, art. 3,

pp. 818-835, Set./Out. 2010

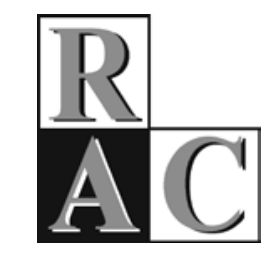

\title{
Processos de Aprendizagem Organizacional no Desenvolvimento de Competências em Instituições de Ensino Superior para a Oferta de Cursos Superiores de Tecnologia [CSTS]
}

\section{Organizational Learning Processes in the Development of Competences in Higher Education Institutions for the Offer of Higher Technological Courses [CSTS]}

\author{
Adriana Roseli Wünsch Takahashi * \\ Doutora em Administração pela USP. \\ Professora de Administração da UFPR, Curitiba/PR, Brasil.
}

André Luiz Fischer Doutor em Administração pela USP. Professor de Administração da FEA/USP, São Paulo/SP, Brasil.

* Endereço: Adriana Roseli Wünsch Takahashi

Universidade Federal do Paraná. Av. Pref. Lothário Meissner, 632, Jardim Botânico, Curitiba/PR, 80210-170.

E-mail: adrianarwt@terra.com.br

Copyright (C) 2010 RAC. Todos os direitos, inclusive de tradução, são reservados. É permitido citar parte de artigos sem autorização prévia desde que seja identificada a fonte. 


\section{RESUMO}

O propósito deste artigo é analisar os processos da aprendizagem organizacional que levaram ao desenvolvimento das competências necessárias para que instituições de ensino superior passassem a oferecer Cursos Superiores de Tecnologia [CSTs]. O escopo do estudo está limitado à cidade de Curitiba-PR e seus pressupostos assumem que a aprendizagem organizacional é o meio pelo qual as instituições adquirem as competências necessárias para viabilizar suas estratégias. A natureza da pesquisa é exploratória, de abordagem qualitativa, e o método utilizado é o estudo de casos múltiplos, em perspectiva longitudinal. Os resultados mostraram que o desenvolvimento da competência de ofertar CSTs demandou mudanças profundas na articulação dos recursos das duas instituições estudadas e a institucionalização de novos conhecimentos. Com base nos dados encontrados em cada caso, foi possível conduzir uma análise transversal, que permitiu constatar que determinadas competências podem ser construídas enquanto outras são desconstruídas, configurando o caráter dinâmico do desenvolvimento de competências e do processo de aprendizagem. Assim, foi possível não só corroborar o modelo de análise adotado, de Patriotta (2003), mas também revisá-lo, a fim de incorporar os resultados desta pesquisa teórico-empírica.

Palavras-chave: aprendizagem organizacional; competências; instituições de ensino superior; mudança; conhecimento.

\section{ABSTRACT}

The aim of this article is to analyze the organizational learning processes that led to the development of the necessary competences for higher education institutions to begin offering Higher Technological Courses. The range of this study is limited to Curitiba in Paraná State, and its assumption is that organizational learning is the way for institutions to obtain the necessary competences to make their strategies practical. The nature of this research is exploratory, using a qualitative approach, and the method used is the multiple case study in a longitudinal time perspective. The results of this multiple-case study showed that the development of the competences required profound changes in the articulation of resources in both institutions that were analyzed, in addition to the institutionalization of new knowledge. Based on the data found in each case, it was possible to conduct a transversal analysis, which made it possible to certify that some competences can be built and others extinguished, shaping the dynamic character of the competences and the learning process. Thus, it was possible to corroborate the analysis model that was used (Patriotta, 2003) and suggest advances for it.

Key words: organizational learning; competences; higher education institutions; change; knowledge. 


\section{INTRODUÇÃO}

Os primeiros estudos sobre a aprendizagem organizacional surgiram a partir dos anos cinquenta. Foi, porém, na década de noventa que esse campo se expandiu na teoria e na prática de gestão. Embora já estabelecida, a área apresenta ainda desafios para sua consolidação, entre eles a dificuldade de constatar empiricamente quando e como um processo de aprendizagem ocorre, desafio que aumenta sobremaneira, quando o sujeito desse processo é a organização. Estudos recentes parecem ter encontrado caminhos promissores para superar essas dificuldades, quando introduzem outras categorias conceituais em suas análises. Dentre eles destacam-se aqueles que estabelecem relações entre aprendizagem organizacional e competências, vertente em que se inclui a presente pesquisa.

Este artigo teve por objetivo analisar os processos da aprendizagem organizacional ocorridos em duas instituições de ensino superior que se transformaram, para passar a ofertar Cursos Superiores de Tecnologia [CST]. Como pressuposto considera-se que esse processo de mudança demandou o desenvolvimento de novas competências organizacionais, por meio de experiências de aprendizagem.

A escolha do setor a ser pesquisado não foi aleatória. O mesmo cenário socioeconômico que destacou a importância do conhecimento na sociedade, fazendo emergir os estudos sobre aprendizagem nas organizações, também levou os sistemas educacionais a se redefinirem. Seguindo tendências internacionais, o Brasil buscou alternativas para superar suas carências no sistema educacional e melhorar o nível de qualificação profissional. Uma dessas iniciativas foi a reformulação e o fomento da educação profissional tecnológica, a partir da Lei de Diretrizes e Bases da Educação [LDB] n. 9.394 (1996) e do Decreto Federal 2208 (1997). Com isso, os CSTs, que já existiam no Brasil há 30 anos, ganharam nova dimensão na educação profissional brasileira. Dados censitários apontam um crescimento acelerado na oferta destes cursos nos últimos dez anos. Esse aumento na oferta de CSTs foi resultado de nova postura das instituições de ensino diante das novas exigências legais. Assim, é razoável supor que essa mudança demandou o desenvolvimento de novos conhecimentos e competências organizacionais. A identificação dessas competências e a forma pela qual as instituições buscaram adquiri-las por meio dos processos de aprendizagem são os principais objetivos deste estudo.

O artigo estrutura-se da seguinte forma: no tópico a seguir, apresentam-se os conceitos de competências e de aprendizagem organizacional adotados; em seguida, a metodologia é proposta e os resultados da pesquisa são descritos e analisados; por fim, mostram-se os principais resultados, as contribuições teóricas e práticas para o estudo, e as sugestões futuras de pesquisa.

\section{COMPETÊNCIAS ORGANIZACIONAIS E APRENDIZAGEM ORGANIZACIONAL}

Duas categorias analíticas são centrais para os objetivos deste trabalho: competências organizacionais e aprendizagem organizacional. Com base nesses pressupostos, promoveu-se a seguir uma reflexão sobre cada um dos conceitos e suas possibilidades de interação.

\section{Competências Organizacionais}

O conceito de competência organizacional tem sua origem na evolução da chamada Visão Baseada em Recursos [VBR], do inglês Resource Based View of the Firm [RBV]. De acordo com Barney (2001), essa abordagem é considerada como a mais consistente para determinar vantagem competitiva entre empresas. Segundo a perspectiva da VBR, é a partir da articulação dos recursos, tangíveis ou intangíveis, que a competência é construída, e um recurso é algo que a organização possui ou a que tem acesso, mesmo temporário (Mills, Platts, Bourne, \& Richards, 2002, p. 19). Para Barney e Hesserly (1996), alguns recursos podem ser de difícil imitação e/ou substituição, por sua ambiguidade 
causal e complexidade social, tais como a história da empresa, a sua cultura organizacional e reputação.

A partir da abordagem da VBR e da noção de recursos, diversos autores apresentaram e discutiram o conceito de competência nas últimas décadas (Leonard-Barton, 1992; Lewis \& Gregory, 1996; Prahalad \& Hamel, 1990; Sanchez, Heene, \& Thomas, 1996). Nos anos noventa, esse conceito ganha destaque na área organizacional com o sucesso do conceito de core competence (competências essenciais) formulado por Prahalad e Hamel (1990). Mais recentemente, Mills et al. (2002) afirmam que as competências estão relacionadas ao desempenho das atividades necessárias ao sucesso da empresa. Para avaliar as competências da organização, os autores desenvolveram uma escala, considerando a comparação entre os concorrentes.

Le Boterf (2003) ressalta a importância do caráter sinérgico das competências organizacionais. O autor assinala que a competência organizacional não equivale à soma das competências de seus membros, mas resulta da cooperação e sinergia entre elas. Este é argumento crucial e que distingue os níveis de análise de qualquer estudo que aborde o tema. As competências podem ser analisadas nos níveis individual, grupal e organizacional. No caso do presente estudo, o foco recai no nível organizacional, cujo sujeito é a instituição de ensino que, por meio da aprendizagem, adquire um recurso diferenciado: o conhecimento. Este, por sua vez, é transformado em competência, a partir de sua articulação com os demais recursos aos quais a instituição tem acesso.

Tendo por base os conceitos até aqui apresentados, assume-se neste trabalho que as competências organizacionais se referem a quão bem uma organização desempenha as atividades necessárias a seu sucesso, em face de seus concorrentes (Mills et al., 2002), e que estas são decorrentes da capacidade de combinar, misturar e integrar recursos em produtos e serviços (Prahalad \& Hamel, 1990). Nesse sentido, constituem o resultado da aprendizagem coletiva da organização (Prahalad \& Hamel, 1990), agregando valor econômico à organização e valor social ao indivíduo (Fleury \& Fleury, 2004).

Cabe destacar que competências não são necessariamente estáticas, embora apresentem tendência a persistir, apesar das entradas e saídas dos indivíduos (Turner \& Crawford, 1994). Porém, se ao longo do tempo as organizações formulam diferentes estratégias ou operações, suas competências poderão ter alguma mudança substancial, o que é importante para o futuro da organização. A reformulação de competências, ou reshaping competences, como as designam Turner e Crawford (1994), permite a mudança e a reformulação de atividades. Porém, apenas recentemente os pesquisadores começaram a ponderar a maneira como as organizações desenvolvem e renovam suas competências para responder às mudanças ambientais.

Para analisar esse processo, Teece, Pisano e Shuen (1997, p. 516) propuseram o enfoque das capacidades dinâmicas (dynamic capabilities): "habilidade da firma para integrar, construir, e reconfigurar competências externas e internas em direção às mudanças ambientais”. Este aspecto é importante por salientar o enfoque dinâmico de competências organizacionais. Nesse sentido, Sanchez et al. (1996) e Sanchez (2001), ao estudarem a dinâmica da competição baseada na competência, utilizam os conceitos de manutenção, construção e alavancagem de competências. A manutenção ocorre quando os ativos e capacidades existentes da organização são mantidos em estado de efetividade para uso nas ações atuais da organização; a construção é o processo pelo qual a organização cria ou adquire mudanças qualitativas em seus ativos e capacidades de forma a atingir seus objetivos; finalmente, a alavancagem refere-se à aplicação de competências existentes em novas oportunidades de mercado que requerem mudança qualitativa nos ativos ou capacidades da firma. É importante destacar que o desenvolvimento de competências resulta da aprendizagem coletiva da organização (Prahalad \& Hamel, 1990), ou seja, representa um processo de aprendizagem (Weick, 1991). A partir desse pressuposto aqui considerado, descrevem-se, na próxima seção, a abordagem e os conceitos adotados no estudo da aprendizagem organizacional. 


\section{Aprendizagem Organizacional}

O crescimento das pesquisas em aprendizagem organizacional foi marcado pela diversidade de abordagens, o que fez com que nenhuma teoria ou modelo de aplicação e análise do tema fosse consagrado como definitivo. Assim, apesar da ampla aceitação da importância do conceito e da necessidade de desenvolver uma teoria a esse respeito (Fiol \& Lyles, 1985), o campo apresenta várias controvérsias. Alguns pontos de consenso, porém, podem ser identificados: entre eles, o de que o conceito de aprendizagem organizacional é essencial para a compreensão de como as organizações evoluem ao longo do tempo e, por isso, é conceito dinâmico, que incorpora a noção de mudança contínua, e que integra, de forma sistêmica, os vários níveis organizacionais (Antonello, 2005).

Partindo do enfoque descritivo de aprendizagem organizacional, que a compreende como lente, para analisar os movimentos e processos organizacionais (Prange, 2001), três preocupações nortearam a escolha dos elementos conceituais desta pesquisa da aprendizagem organizacional: conceitos, perspectivas e processos.

No primeiro item, com base na revisão histórica da construção conceitual e da emergência do debate sobre aprendizagem, tanto em autores clássicos, como Cyert e March (1963), March e Olsen (1976), Argyris e Schön (1978), Hedberg (1981), Huber (1995), Cook e Yanow (1993), Weick e Westley (1996), Nonaka e Takeuchi (1997), quanto em autores que realizaram revisão de literatura, tais como Shrivastava (1983), Fiol e Lyles (1985), Prange (2001), Bitencourt (2001), Easterby-Smith e Lyles (2003) e Antonello (2005), foi possível selecionar dimensões relevantes para a proposição de um conceito: processo, noção de mudança, natureza coletiva, criação e reflexão, ação, abordagem contingencial e abordagem cultural (Vasconcelos \& Mascarenhas, 2007). Essas dimensões, acrescidas da dimensão institucional, já apontada na literatura por Shrivastava (1983), nortearam o conceito adotado de aprendizagem organizacional.

Segundo Bitencourt (2001), a aprendizagem organizacional tem dois componentes importantes: os insights e a memória organizacional. Os insights são os conhecimentos e modelos mentais compartilhados e que os decisores devem aprender juntos, para não bloquear a mudança. A memória organizacional depende dos mecanismos institucionais para reter o conhecimento. Conhecimento, crenças e metas precisam ser compartilhados na construção da memória organizacional, para que a organização aprenda. Tal definição reforça os elementos consensuais, já apontados por outros autores na literatura, e complementa o caráter abrangente da aprendizagem no âmbito coletivo. Contudo, a área de aprendizagem organizacional tem sofrido profundas mudanças e deverá continuar mudando nos próximos dez anos, parecendo haver concordância de que processo, conteúdo e questões de contexto permanecerão como relevantes tópicos de pesquisa no futuro (Lyles \& Easterby-Smith, 2003).

No segundo tópico, consideramos as vertentes em que se privilegiam os enfoques comportamental, cognitivo e sociocultural, e se busca considerar a complementaridade dessas perspectivas. Nicolini e Meznar (1995) advertiram que a distinção entre a abordagem comportamental e cognitiva é inadequada, para servir de base em definir a aprendizagem organizacional, porque ela estreita os limites do fenômeno e obscurece a relação entre as duas formas de mudança organizacional. De acordo com os autores, a aprendizagem organizacional é fenômeno que precisa ser examinado em sua totalidade, pois não envolve somente o processo de aquisição de conhecimento, mas também o papel que a construção social da aprendizagem organizacional tem na formação da organização em si. Isso inclui a modificação das estruturas cognitivas e o processo de representação, formalização e normalização de tais conhecimentos, ou seja, inclui a perspectiva cultural. Como bem salientam Guarido Filho e Machado-da-Silva (2001), a aprendizagem organizacional fundamentada numa lógica integradora, que abrange também aspectos culturais e institucionais, permitindo que ela seja compreendida como processo contínuo e culturalmente articulado no contexto social. O estudo das perspectivas permitiu identificar como observar esse fenômeno.

No entanto, analisar a aprendizagem organizacional do ponto de vista mais amplo, que agrega aspectos sociais e institucionais ao conceito, implica uma visão de processo. Essa foi a terceira 
preocupação, que possibilitou delinear um caminho para abordar os processos da aprendizagem organizacional. Mudança e conhecimento emergiram desse debate como pontos de consenso entre as diversas perspectivas consultadas (Antonello, 2005; Bitencourt, 2001). Discutiu-se também em que medida os resultados encontrados podem configurar o que se chama de aprendizagem no nível organizacional.

Quanto à mudança, autores como Argyris e Schön (1978), Fiol e Lyles (1985) e Barr, Stimpert e Huff (1992), relacionaram tipos de aprendizagem a diferentes tipos de mudança. Respectivamente, a aprendizagem single loop, de nível inferior e de baixo grau, está associada a mudanças incrementais, de pequeno impacto e de racionalidade funcional. A aprendizagem double loop, de nível superior e de alto grau, está vinculada à mudança nos valores organizacionais, nos esquemas interpretativos e, portanto, à cultura organizacional.

Quanto ao conhecimento, a aprendizagem organizacional, apesar das divergências acadêmicas, apresenta, em suas definições, a importância da aquisição, melhoria e transferência do conhecimento (Fischer \& Silva, 2004). Segundo Patriotta (2003), as teorias correntes de conhecimento parecem privilegiar a criação do conhecimento, em vez da dinâmica da institucionalização. O autor salienta a necessidade de avançar no estudo da dinâmica da institucionalização do conhecimento como processo pelo qual componentes significantes do conhecimento e da ação humana são registrados e delegados em estruturas de significação estáveis, e de relacioná-la com a aprendizagem organizacional. Uma reflexão importante do autor é a de que o conhecimento tácito não é propriedade ou conversão de estado, pois está relacionado aos problemas de pré-interpretação: “A realidade é necessariamente apreendida por meio de lentes socialmente construídas, que se tem sedimentado ao longo do tempo" (Patriotta, 2003, p. 60). Essa ponderação converge em uma perspectiva de aprendizagem que abarca aspectos culturais. Cabe ainda destacar que, para o autor, os 'backgrounds' que governam as práticas diárias da organização são tanto fonte quanto resultado do conhecimento humano, e sua configuração particular resulta de três importantes fatores: a) a história, como resultado da sedimentação das experiências de aprendizagem pelo tempo; b) o hábito, pois quando o conhecimento é profundamente internalizado e institucionalizado, tende a ser usado de forma quase automática e impensada; e c) a experiência, pois o conhecimento pela definição tácita está relacionado a ela. A partir de tais escolhas teóricas, identificam-se na literatura modelos sustentados empiricamente, que integram as categorias de competências e aprendizagem no nível organizacional. Dentre eles, destaca-se o de Patriotta (2003), porque o autor enfatiza a dinâmica da institucionalização do conhecimento e os processos de mudança e estabilidade organizacional Seu estudo resultou em modelo classificatório de conhecimento, que se adotou aqui como referência, por abordar conteúdo, contexto e processo do conhecimento, e por adicionar ao debate o papel da institucionalização, que confere particular consistência ao processo de aprendizagem, quando ela se localiza no plano institucional.

O estudo de Patriotta (2003), de caráter longitudinal, foi aplicado a três casos em duas plantas industriais da Fiat na Itália. Os três fatores (história, hábito e experiência) constituem, no estudo empírico do autor, as lentes como ferramentas operacionais para estudar o processo do conhecimento: o tempo, as interrupções e/ou gargalos na produção, e as narrativas. O tempo refere-se à dinâmica do tornar-se social; as interrupções referem-se às formas habituais de fazer as coisas, os padrões de rotinização; e as narrativas são um dispositivo de sensemaking que fornecem modos distintivos de conhecer, por meio do qual o conhecimento relacionado à experiência é articulado em algumas formas de discurso organizacional. Essas lentes apontam as descontinuidades no tempo, na ação e na experiência, para a dinâmica da criação do conhecimento ao inverso.

Dois casos foram investigados em nova planta com baixo grau de institucionalização do conhecimento, e outro em antiga planta com alto grau de institucionalização do conhecimento. A primeira planta, em Melfi, aberta em 1994, envolveu dois casos: a) a implantação de uma planta nova (greenfield) com novos funcionários, treinamento e localização; b) a colocação dessa planta em plena atividade. O terceiro caso foi o da planta de Mirafiori (brownfield), aberta aproximadamente em 1950 e ainda em atividade. 
O objetivo do autor foi contribuir para preencher a lacuna entre a teoria, o método e a prática no estudo do conhecimento e da aprendizagem nas organizações. Diferentes processos de aprendizagem foram observados nos três casos, relacionados ao desenvolvimento de determinadas competências. O modelo resultante desse estudo pode ser visualizado na Figura 1:

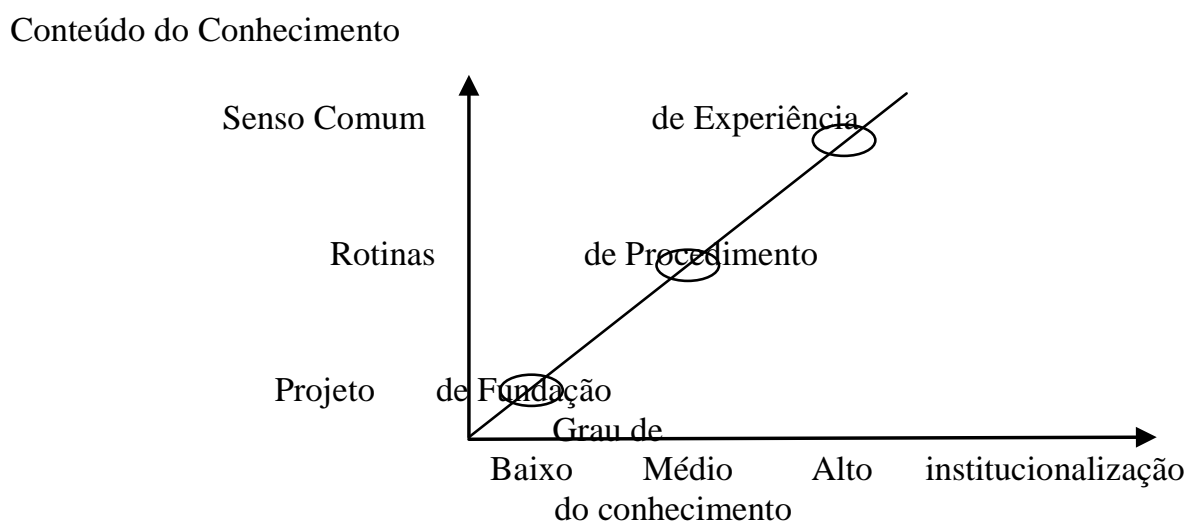

Figura 1. Um Sistema Classificatório de Conhecimento em Organizações

Fonte: Patriotta, G. (2003). Organizational knowledge in the making: how firms create, use, and institutionalize knowledge (p. 193). United States: Oxford University Press.

O modelo de Patriotta (2003) abrange um ciclo de conhecimento baseado em processos recursivos de criação, utilização e institucionalização do conhecimento. Nesse modelo, os principais conteúdos do conhecimento nos três casos foram, respectivamente, identificados como: projetos (da montagem dos carros), rotinas (da fábrica) e senso comum (sobre seu funcionamento). O projeto de uma planta foi transformado, no primeiro caso, em um produto hard (no caso a fábrica) e foi articulado a seu funcionamento. As rotinas estabelecidas a partir do funcionamento da fábrica, no segundo caso, representam o conhecimento embutido e procedimentalizado, tornando-o algo transparente. Neste caso, há um processo mais avançado de criação e institucionalização do conhecimento centrado nas práticas do trabalho e relacionado à utilização do conhecimento existente. O senso comum é o resultado de um processo de aprendizagem profundamente situado, em que o conhecimento é armazenado nas experiências e se torna parte da memória organizacional. A sabedoria do senso comum está representada no discurso organizacional: narrativas, histórias, piadas, histórias de conflitos. Essa sequência não significa que os outros conhecimentos desapareceram, mas que foram tidos por certos (taken for granted).

Da intersecção entre conteúdo do conhecimento e grau de institucionalização (a primeira fábrica em ambiente de baixa e média institucionalização, por ser nova, e a segunda fábrica em ambiente altamente institucionalizado, por ser antiga) resultou um sistema classificatório com tipos específicos de conhecimento: a) de fundação, ligado ao delineamento da nova fábrica, que relaciona a natureza do conhecimento organizacional à origem daquele conhecimento, no caso ao projeto dos carros; b) de procedimento, referente ao caráter rotinizado da ação organizacional em ambientes de trabalho consolidados, nas linhas de montagem e c) de experiência, relativo a estágios mais maduros na trajetória evolucionária do conhecimento e organização, perpetuados por meio das histórias organizacionais. O ciclo do conhecimento liga sistematicamente o conteúdo do conhecimento, o processo e o contexto.

Esse modelo permite vincular o estudo da aprendizagem organizacional ao tipo e grau de profundidade da mudança e ao fluxo do conhecimento nas organizações (da criação à institucionalização do conhecimento). Tais elementos apoiaram a definição de requisitos para considerar quando e por que a aprendizagem é organizacional. A aprendizagem organizacional referese ao processo de mudança transformacional, que envolve dinamicamente os vários níveis (indivíduos, grupos e organização) e pelo qual se dá a criação, utilização e institucionalização do conhecimento. Ela opera no âmbito coletivo, abrangendo aspectos cognitivos, comportamentais e culturais. Seu 
resultado, ou conteúdo, é o próprio conhecimento, fonte e resultado de seu background (história, hábitos e experiências), expresso no desenvolvimento das competências organizacionais (aquisição, alavancagem ou manutenção).

O modelo adotado permite também vincular o estudo da aprendizagem organizacional ao desenvolvimento de competências. No primeiro caso, a progressiva apropriação da fábrica por seus usuários finais resultou na aquisição de competências distintivas baseadas na identidade entre a experiência de montagem da fábrica no campo de construção e a tarefa de montagem do carro no chão de fábrica. No segundo caso, as competências adquiridas pelos trabalhadores e gerentes, na fase de construção, foram aplicadas no contexto prático do processo produtivo, ou seja, a competência de montar um carro. No terceiro caso, pela natureza arquetípica dos modelos por meio dos quais o conhecimento é armazenado na memória organizacional, imitado e replicado, as competências são mantidas na rotina da fábrica.

Em suma, o modelo de Patriotta (2003) traz importantes contribuições para a compreensão do processo de aprendizagem organizacional no desenvolvimento de competências. Na próxima seção apresenta-se a metodologia utilizada e o modo como o modelo escolhido foi adaptado à pesquisa empírica de acordo com os conceitos adotados.

\section{Escolhas Metodológicas e Seleção dos Casos}

Para atingir o objetivo proposto, o método utilizado foi o de estudos de casos múltiplos em profundidade (Eisenhardt, 1989; Richardson, 1989). Buscou-se tratar cuidadosamente as particularidades de cada caso e, posteriormente, obter evidências mais convincentes e robustas (Yin, 2005) nas conclusões. A abordagem é qualitativa (Creswell, 2002), exploratória (Selltiz, Wrightsman, \& Cook, 1987), com perspectiva longitudinal a partir de um corte transversal no período de dois anos anteriores à data do evento identificado (1994). O evento refere-se à alteração legal, que regulamenta a Educação Profissional no Brasil, iniciada com a LDB em 1996 (LDB n. 9.394, 1996). O nível de análise é organizacional e a unidade de observação é composta pelo grupo de gestores (dirigentes e coordenadores de cursos) e docentes envolvidos na implantação dos CSTs.

Para a exploração dos objetivos de pesquisa, adotaram-se três pressupostos (Eisenhardt, 1989) que emergiram da revisão de literatura:

- P1 - competências organizacionais são dinâmicas, não estáticas, e desenvolvidas pela articulação nas diversas categorias de recursos;

- P2 - a aprendizagem organizacional envolve mudanças significativas na articulação dos recursos, é coletiva e ocorre na interação social do trabalho, e implica a institucionalização dos conhecimentos criados e utilizados (registros na memória organizacional, legitimidade e incorporação nas rotinas e práticas);

- P3 - existe relação entre processos de aprendizagem organizacional, conhecimento e desenvolvimento de competências organizacionais.

Após a pesquisa bibliográfica e a contextualização do setor escolhido para o estudo, adotou-se um modelo operacional de pesquisa, a partir do modelo conceitual (constructo), que seguiu passos previamente definidos. O primeiro passo foi a identificação dos dados de cada organização, em que se procurou avaliar suas particularidades e como os eventos afetaram a organização. O segundo passo consistiu na identificação do processo de decisão de oferta dos cursos tecnológicos, tendo em vista os eventos anteriormente analisados. Em um terceiro momento, identificaram-se e avaliaram-se as competências organizacionais desenvolvidas pelas duas instituições para ofertar CSTs. Machado-daSilva, Fonseca e Crubellate (2005, pp. 32-33), ao se referirem aos delineamentos metodológicos de 
averiguação empírica que atendam aos requisitos para uma abordagem sistêmico-processual, apontam: "Fotos de uma configuração social, típicas de um corte transversal, podem se constituir em primeiro passo de um processo de pesquisa longitudinal e histórica para desvelar o filme que levou àquela configuração". Nesse sentido, a foto da competência organizacional foi pertinente, como passo para verificar os processos de aprendizagem organizacional.

A descrição do processo de implantação dos CSTs ocorreu no quarto momento, quando se investigaram a articulação das mudanças ocorridas nas diversas categorias de recursos (Mills et al., 2002) e o fluxo de conhecimento (criação, utilização e institucionalização), por meio da análise retroativa no tempo e na ação (Patriotta, 2003). Empiricamente, nos casos selecionados, aplicou-se a lógica metodológica subjacente ao modelo de Patriotta (2003). Como relatado anteriormente, o autor estudou três casos em duas plantas industriais. Neste trabalho buscaram-se as mesmas relações em três momentos diferentes de duas instituições de ensino superior, definidos por critério temporal: préimplantação, implantação e pós-implantação dos cursos tecnológicos. Assim, as duas organizações (casos) representam, neste estudo, seis configurações particulares, com suas respectivas características e contextos. Uma quarta fase, chamada de fase futura, foi considerada, a fim de identificar registros das mudanças ocorridas na memória organizacional, como evidência da institucionalização do conhecimento e do nível organizacional de aprendizagem. Essa etapa abrangeu a análise da evolução da aceitação organizacional e social dos cursos tecnológicos.

O quinto passo consistiu na análise do processo de aprendizagem organizacional de cada caso em particular e dos resultados comuns aos dois casos estudados. Por fim, no último passo, realizou-se a análise da inter-relação de aprendizagem organizacional com o desenvolvimento de competências organizacionais.

As fontes dos dados coletados são primárias e secundárias. Utilizaram-se entrevistas, pesquisa documental e observação não participante. Os dados foram registrados, gravados, transcritos e catalogados. Ao total foram realizadas 39 entrevistas com duração média de uma hora, sendo 22 na primeira e 17 na segunda instituição. Os dados obtidos na observação foram registrados em um diário de campo. Para a análise dos dados, utilizou-se a técnica de análise documental, de análise de conteúdo (Bardin, 1979) e a técnica de triangulação dos dados (Triviños, 1987). Inicialmente, procurou-se apreender e descrever a realidade de cada caso para, posteriormente, conduzir uma análise transversal dos dois casos.

A população é composta pelo grupo de instituições de ensino superior ofertantes de CSTs no Brasil. Entrevistas informais mediaram a aproximação ao campo de pesquisa. A amostra foi definida por acessibilidade e conveniência. Três critérios foram utilizados: a) ofertantes de CSTs há pelo menos dois anos; b) localizadas em Curitiba-PR; e c) dispostas a participar da pesquisa. No final, duas instituições atenderam aos requisitos: a unidade de Curitiba do Centro Federal de Educação Tecnológica do Paraná [CEFET-PR], hoje Universidade Tecnológica Federal do Paraná [UTFPR] e o Centro de Educação Tecnológica Opet (hoje Faculdade de Tecnologia Opet).

\section{ResUlTADOS DA PESQUISA}

Neste artigo, optou-se por descrever, de forma sintetizada, os principais achados individuais de cada caso realizado, a fim de aprofundar a análise transversal e a discussão dos resultados, priorizando, assim, as contribuições deste trabalho teórico-empírico no campo de aprendizagem organizacional no desenvolvimento de competências. 


\section{Descrição dos Casos}

O CEFET-PR tem suas raízes em 1909. Atualmente, possui 11 campi no estado do Paraná. Na unidade de Curitiba, são ofertados cursos técnicos de nível médio, cursos superiores de tecnologia, cursos de graduação, cursos de pós-graduação, além dos cursos extraordinários de especialização e de formação pedagógica. O Grupo Opet é uma empresa privada e familiar, fundada em 1973, a partir da visão empreendedora de seu fundador. Sua história está ligada, desde o início, à oferta de cursos profissionalizantes e técnicos. Em 1999 criou o Centro de Educação Tecnológica [CET-Opet], passando a ofertar os CSTs, a partir de 2001. Atualmente, oferta cursos tecnológicos nas áreas de informática, comunicação, comércio e gestão.

Entre os principais eventos (Zarifian, 2003) identificados, estão as mudanças legais e normativas ocorridas na educação profissional e tecnológica, a partir da LDB de 1996, com destaque do Decreto n. 2208 (1997) e da Portaria n. 646, do mesmo ano (1997), que proibiu a oferta dos cursos técnicos integrados no ensino médio, uma atividade central em ambas as instituições. Essas mudanças ambientais causaram significativo impacto nas duas instituições, que optaram pela oferta dos CSTs. Outros fatores, no entanto, influenciaram essa decisão: no caso do CEFET-PR, o desejo dos dirigentes de transformá-lo em universidade; no caso da Opet, a oportunidade de ser pioneiro na oferta desta modalidade de ensino no setor privado na região sul do país.

Apesar da experiência na oferta de cursos técnicos, a oferta de CSTs demandou competências específicas das duas instituições, embora já existisse uma sintonia entre a educação profissional tecnológica e os valores organizacionais. Conhecimentos anteriores foram particularmente úteis na fase de pré-implantação dos novos cursos, e favoreceram o desenvolvimento da nova competência organizacional de ofertar CSTs, uma competência que ambas as instituições avaliaram possuir como muito alta em face dos seus concorrentes. A análise do desenvolvimento dessa competência organizacional permitiu verificar quais foram os conhecimentos obtidos, a profundidade das mudanças ocorridas nos recursos organizacionais, segundo a categorização de Mills et al. (2002), e como essas mudanças foram articuladas para desenvolver a competência organizacional de ofertar CSTs. A Tabela 1 sintetiza os resultados encontrados.

Tabela 1

Mudança e Conhecimento na Implantação dos Cursos Superiores de Tecnologia na Unidade de Curitiba do CEFET-PR e no CET-Opet

\begin{tabular}{|c|c|c|c|}
\hline \multirow{2}{*}{$\begin{array}{l}\text { CATEGORIA DE } \\
\text { RECURSOS }\end{array}$} & \multirow{2}{*}{ CONHECIMENTO (sobre) } & \multicolumn{2}{|c|}{ PROFUNDIDADE DAS MUDANÇAS } \\
\hline & & CEFET/PR-CURITIBA & CET -OPET \\
\hline Tangíveis & $\begin{array}{l}\text {-Exigências legais de estrutura } \\
\text { física }\end{array}$ & Incremental & Transformacional \\
\hline $\begin{array}{l}\text { Conhecimentos, } \\
\text { habilidades e } \\
\text { experiência }\end{array}$ & $\begin{array}{l}\text { - CSTs (projetos, estrutura) } \\
\text {-Metodologia de ensino e práticas } \\
\text { - ensino/avaliação }\end{array}$ & $\begin{array}{l}\text { Transformacional } \\
\text { Incremental }\end{array}$ & Transformacional \\
\hline $\begin{array}{l}\text { Sistemas e } \\
\text { procedimentos }\end{array}$ & $\begin{array}{l}\text {-Gerenciamento dos CSTs } \\
\text {-Domínio do sistema de ensino }\end{array}$ & $\begin{array}{l}\text { Transformacional } \\
\text { Incremental }\end{array}$ & Transformacional \\
\hline Culturais e de valores & $\begin{array}{l}\text {-Incorporação de novos } \\
\text { pressupostos e preservação de } \\
\text { valores centrais }\end{array}$ & Transformacional & Transformacional \\
\hline $\begin{array}{l}\text { Redes de } \\
\text { relacionamentos }\end{array}$ & $\begin{array}{l}\text {-Mercado de trabalho dos } \\
\text { tecnólogos }\end{array}$ & Incremental & Transformacional \\
\hline $\begin{array}{l}\text { Importantes para } \\
\text { mudanças }\end{array}$ & $\begin{array}{l}\text {-Monitoração das pressões } \\
\text { ambientais da ET e CSTs }\end{array}$ & Transformacional & Transformacional \\
\hline
\end{tabular}

Nota. Fonte: Elaborado pelos autores com base nos dados da pesquisa. 
Os conhecimentos adquiridos na implantação dos CSTs envolveram aspectos legais, aspectos pedagógicos (projetos de curso, práticas de ensino, metodologia, avaliação), aspectos gerenciais (sistema de ensino, registro acadêmico, atualização e acompanhamento dos cursos), aspectos mercadológicos e aspectos relacionais (internos e de integração com o mercado de trabalho). Em ambos os casos, os recursos organizacionais culturais implicaram a incorporação de novos valores referentes à legitimidade dos CSTs, embora valores centrais tenham sido preservados.

No caso da unidade de Curitiba do CEFET-PR, verificou-se que algumas mudanças foram incrementais, em determinada atividade; assim, foram de pequeno impacto, enquanto outras foram significativas, nos modelos mentais, na reflexidade e nos valores e, por isso, transformacionais (Barr et al., 1992). No caso do CET-Opet, verificou-se que todas as mudanças ocorridas nas diversas categorias de recursos foram de significativo impacto, atingindo a cultura organizacional. O CETOpet, por ser uma unidade nova, desenvolveu pressupostos próprios na educação tecnológica, nos cursos tecnológicos e na sua forma de atuação. As mudanças incrementais conduziram à aprendizagem de circuito simples, de nível inferior, ou ainda, de baixo grau, enquanto as mudanças transformacionais evidenciaram a ocorrência da aprendizagem de circuito duplo, de nível superior, ou ainda, de alto grau (Argyris \& Schön, 1978; Barr et al., 1992; Fiol \& Lyles, 1985).

Com base nos resultados obtidos, avançou-se na busca de uma análise integrada, a partir de características similares na experiência vivenciada pelas duas instituições de ensino.

\section{Discussão e Análise dos Resultados}

Nos dois casos estudados, verificou-se que a competência organizacional de ofertar CSTs está alinhada com os valores organizacionais, o que facilitou a mobilização de recursos para o seu desenvolvimento. Dentre as atividades que envolvem os recursos, três em cada organização foram tão importantes para a competência organizacional, que puderam ser classificadas como competências de suporte (Mills et al., 2002). No caso do CEFET-PR, atividades relacionadas ao corpo docente, interação com o mercado e estrutura física; no caso do CET-Opet, relacionadas à sinergia com o mercado, aos aspectos pedagógicos e ao corpo docente. Essas constatações corroboram afirmação de Barney e Hesserly (1996) de que a história da empresa é única e que alguns de seus recursos podem ser de difícil substituição, ou imitação, como a cultura organizacional e a reputação. É necessário destacar que se trata de uma organização pública e de uma organização privada, em que a relação com os docentes e com o mercado se dá de diferentes formas. Assim, enquanto algumas competências organizacionais foram mantidas e alavancadas, outras foram construídas (Sanchez, 2001; Sanchez et al., 1996).

Nas três fases consideradas dentro do processo de implantação dos CSTs, os conhecimentos criados foram incorporados na rotina organizacional, indicando que houve um processo de institucionalização de tais conhecimentos, registrados nos projetos de curso e manuais, entre outros documentos da organização. Dessa forma, passaram a fazer parte da memória organizacional (Hedberg, 1981), ficando registrados em sua história. As mudanças decorrentes desse processo foram, em sua maioria, transformacionais. A modalidade de ensino tecnológico passou então a fazer parte das estratégias da organização e seus planos futuros já não questionam a permanência ou a razão de sua existência, mas a adequação aos propósitos organizacionais e ao mercado de trabalho.

Os projetos dos CSTs representam o produto que nasceu do processo de aprendizagem, resultado do esforço coletivo e da quebra das barreiras internas. Na segunda e na terceira fase, que foi de implantação e pós-implantação, o processo de aprendizagem foi referente à operacionalização e manutenção dos CSTs. Nessas duas fases, o principal resultado foi o domínio das próprias rotinas relativas ao ensino, avaliação, relacionamento e gestão, e a construção do senso comum em torno da validade dos cursos. Na interface dos processos (criação, implantação e manutenção) e resultados da aprendizagem (projetos, rotinas e senso comum), observou-se um ciclo de desenvolvimento do conhecimento referente à educação tecnológica, que foi criado, utilizado e institucionalizado. 
Esses resultados permitiram validar o modelo teórico de Patriotta (2003), ao evidenciar a relação entre conteúdo, processo e contexto do conhecimento no processo de aprendizagem organizacional e ao apontar os mesmos resultados do conhecimento - de fundação, de procedimentos e de experiência em ambientes de baixo, médio e alto grau de institucionalização. A gradativa apropriação do conhecimento criado está associada ao produto (cursos tecnológicos), ao processo (atividades de ensino e pesquisa) e ao público (alunos e mercado). A transferência do conhecimento ocorreu na prática das atividades, no contexto do trabalho e por meio dos mecanismos de interação e socialização, formais e informais. Isso destaca a natureza social da aprendizagem: o que é aprendido está vinculado ao contexto, ao conhecimento de base dos atores, à história e à cultura da organização. É, portanto, como observou Patriotta (2003), ao longo do tempo que as práticas passam a ter sentido e que o senso comum é construído.

Atualmente, as histórias narradas sobre a implantação dos CSTs constituem um mecanismo de retenção do conhecimento (Patriotta, 2003). Esses registros, orais e escritos, são o resultado da institucionalização, que é justamente a incorporação de conhecimento e ação em dispositivos organizacionais estáveis: estrutura, rotinas, mapas cognitivos (Patriotta, 2003). O padrão de atividades desenvolvido foi possuído normativa e cognitivamente, tido como certo, como legítimo (Scott \& Meyer, 1994).

A aprendizagem observada nos dois casos estudados foi, portanto, de nível organizacional, porque envolveu não somente mudanças profundas e significativas, mas também a institucionalização do conhecimento nas práticas, rotinas e estratégias. Ela ocorreu devido às modificações na estratégia: normas e pressupostos embutidos na memória organizacional. Como processo social, ela emergiu das relações no ambiente natural de trabalho, tornando-se coletiva, porque se deu na interação social (Cook \& Yanow, 1993). Por isso, ela representou mais do que uma simples soma (Hedberg, 1981) das aprendizagens individuais e foi além da cognição individual (Weick \& Westley, 1996). Dessa forma, no âmbito deste trabalho, pôde-se confirmar o conceito adotado de aprendizagem organizacional. Esse conceito também confirma os pontos de consenso verificados na literatura por Shrivastava (1983), Fiol e Lyles (1985), Prange (2001), Bitencourt (2001) e Antonello (2005). Ao falar de aprendizagem organizacional, constatou-se ser difícil distingui-la da aprendizagem individual.

Todavia, o estudo múltiplo de casos permitiu avançar nos resultados. Primeiro, observou-se que as duas organizações estudadas estão ainda na terceira fase, aquela de apropriação do conhecimento de experiência (Patriotta, 2003) na oferta de CSTs. Em segundo lugar, e mais importante, cabe observar que, nos casos estudados, diferentemente da pesquisa empírica de Patriotta (2003), eventos interromperam práticas e rotinas anteriormente institucionalizadas. Portanto, enquanto novos conhecimentos foram incorporados num processo recursivo de criação, utilização e institucionalização de conhecimentos, provocando mudanças na articulação dos recursos, outros caíram em desuso, provocando a interrupção de práticas vigentes. Isso não significa, no entanto, que se abandonaram todos os conhecimentos anteriores. Eles foram, até mesmo relevantes para o primeiro ano de atividade dos cursos tecnológicos, foram articulados para compor outra competência. Esta constatação chama a atenção para os antecedentes da mudança, ou para os determinantes da desinstitucionalização. Neste momento, resgatou-se o trabalho de Oliver (1992), para que se pudessem analisar os dois movimentos - de institucionalização e desinstitucionalização do conhecimento. A autora adverte que a compreensão da institucionalização também depende da investigação do processo pelo qual organizações reconstroem a realidade, quando valores e práticas existentes são rejeitados ou invalidados. Esse parece ser o caso nesta pesquisa. Dessa forma, foi possível avançar na análise integrada dos casos para realizar as contribuições finais do estudo teórico-empírico.

\section{Contribuições do Estudo Teórico-Empírico}

Pôde-se observar a presença de indicadores empíricos de desinstitucionalização nos dois casos: pressões sociais, funcionais e políticas (Oliver, 1992). Tais pressões determinaram a desinstitucionalização de uma prática de ensino e de determinados tipos de conhecimento. Nesse momento, retomou-se o modelo assumido (Patriotta, 2003) e agregou-se a mudança constatada, que 
expressa o processo de aprendizagem organizacional na (des)construção da competência organizacional durante a (des)institucionalização do conhecimento. Portanto, procurou-se avançar das contribuições da teoria para as contribuições para a teoria (Eisenhardt, 1989). A Figura 2 sintetiza o processo averiguado, observado pela lente do tempo, e representa um avanço no modelo do autor, ao ampliar a análise (na descontinuidade) do tempo e (na desconstrução) da ação nos casos estudados:

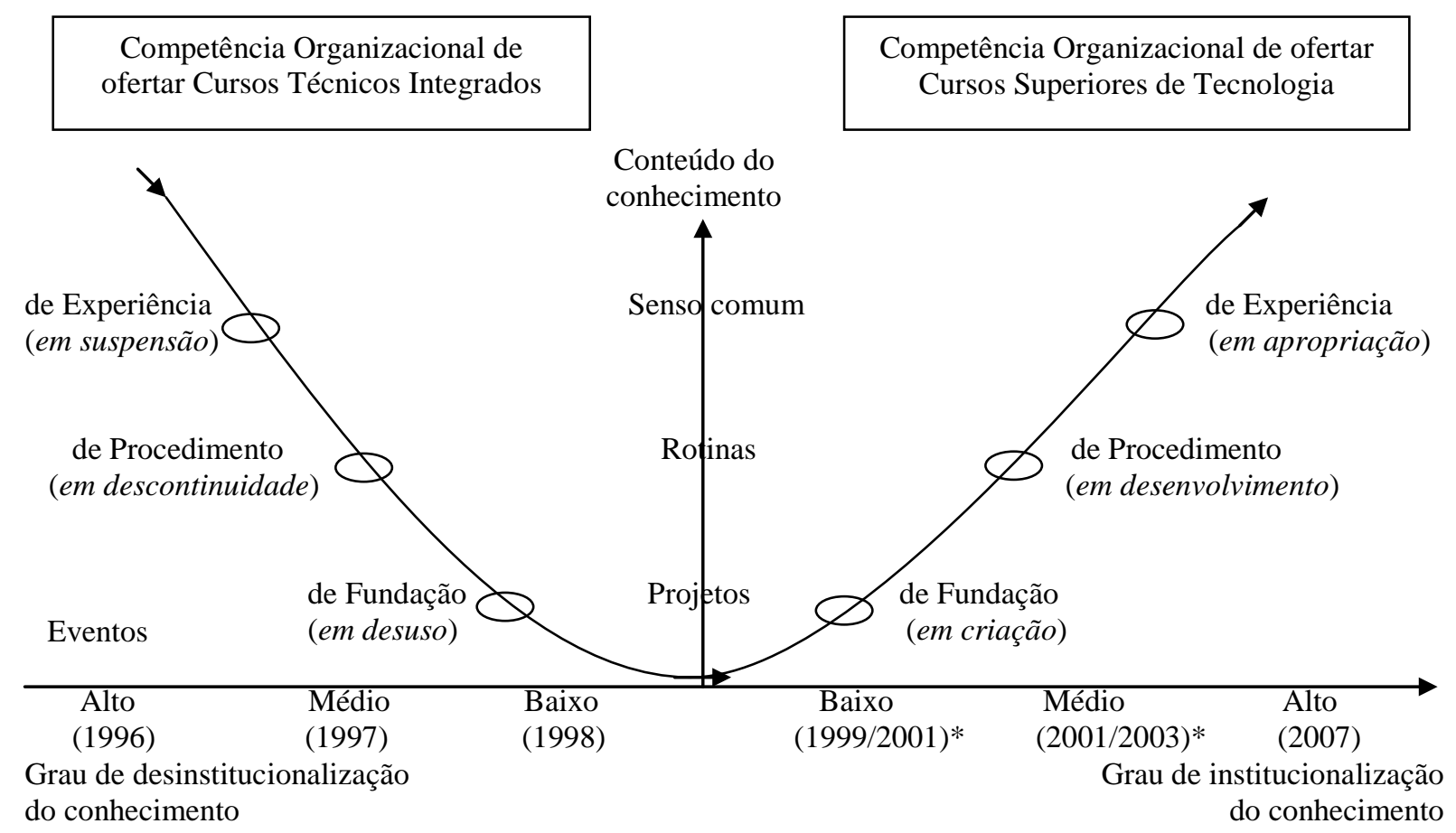

Figura 2. Sistema Classificatório de Institucionalização e Desinstitucionalização do Conhecimento em Organizações

Fonte: Elaborado pelos autores com base nos dados da pesquisa.

A partir dos eventos, o conhecimento de Experiência nos cursos técnicos integrados foi mantido em suspensão com a descontinuidade dos procedimentos e o desuso da oferta desses cursos. Por outro lado, outras práticas foram desenvolvidas com a criação dos cursos tecnológicos, que, com o tempo, trouxeram experiências que foram incorporadas. Ou seja, as rotinas relativas aos cursos técnicos integrados, antes incorporadas, foram descontinuadas, enquanto outras foram desenvolvidas, gerando um novo conhecimento Procedimental. Com a construção do senso comum em torno das novas rotinas, o conhecimento de Experiência foi sendo apropriado na organização. A regressão do uso do conhecimento (suspensão, descontinuidade e desuso), referente a oferta de cursos técnicos integrados, configura um processo de desinstitucionalização, em que o conhecimento antes institucionalizado perde importância no tempo. A progressão na aquisição e aplicação do conhecimento (criação, desenvolvimento e apropriação) envolvido na construção da competência organizacional de ofertar cursos tecnológicos configura um processo de institucionalização, no qual o conhecimento ganha intensidade com o passar do tempo, e ganha com a experiência. Atestando a afirmação de Oliver (1992), o resultado foi caracterizado pelo processo de institucionalização de uma prática de ensino em prol da gradativa desinstitucionalização de outra.

Anteriormente ao processo de desinstitucionalização, as instituições também viveram um processo de aprendizagem organizacional no desenvolvimento da competência de ofertar cursos técnicos integrados, o que aponta o caráter contínuo, tanto do desenvolvimento de competências quanto da própria aprendizagem organizacional. Apesar do desenvolvimento de nova competência organizacional, a anterior, de ofertar cursos técnicos integrados, institucionalizada ao longo de décadas de experiência, não foi perdida, apenas atrofiada. Posteriormente, com o retorno da autorização legal 
da oferta de cursos técnicos integrados, aqueles cursos foram retomados, mas com pouca ênfase, pois já não tinham a mesma importância para as organizações.

Para as duas organizações estudadas, o desenvolvimento de novas competências foram importantes na medida em que propiciaram crescimento e mudanças em seu perfil. Portanto, se competências podem ser construídas, alavancadas e mantidas (Sanchez, 2001), o movimento inverso pode também ocorrer: elas podem ser descartadas ou atrofiadas. Portanto, a habilidade de renovação de competências foi observada nos dois casos, apresentando, ainda que em graus diferentes, o que Teece et al. (1997) chamam de capacidades dinâmicas (dynamic capabilities). Apesar da inércia típica do setor educacional, verificou-se que as organizações têm consciência da necessidade de mudança, o que é, segundo Mills et al. (2002), a característica da capacidade dinâmica, competência que determina a adaptação de todas as competências ou atividades no tempo. Corroborou-se também a afirmação de Zollo e Winter (2002), de que, mesmo quando o início do desenvolvimento de competências organizacionais é causado por esforços de ajuste às mudanças ambientais, de forma reativa, as mudanças organizacionais desencadeadas podem conduzir processos de aprendizagem organizacional e despertar ou alavancar a capacidade dinâmica da organização, uma vez que ela pode passar a monitorar mais seu ambiente e a planejar novas mudanças.

Neste ponto, com base nas análises e considerações aqui apresentadas, confirmaram-se os três pressupostos estabelecidos neste trabalho: o de que competências organizacionais são dinâmicas e desenvolvidas por meio da articulação dos recursos (P1); o de que a aprendizagem organizacional envolve mudanças significativas nos recursos, é coletiva e se dá na interação social do trabalho, e implica a institucionalização dos conhecimentos criados e utilizados (P2); e o de que há uma relação coerente entre processos de aprendizagem organizacional e desenvolvimento de competências organizacionais (P3). Produtos (cursos) representam a manifestação das competências (ofertar os cursos), assim como competências podem ser moldadas em uma variedade de produtos. Corroborando a afirmação de Weick (1991), o resultado da aprendizagem organizacional é a aquisição de uma competência que representa esse processo, cujas habilidades envolvidas permitem aplicar novos conhecimentos para melhorar o desempenho existente ou para preparar para novas circunstâncias. Usando de uma metáfora, verificou-se que as competências de uma organização representam o DNA da aprendizagem organizacional. Isso implica ver as competências em movimento, mudando no tempo e no contexto da organização, de acordo com os eventos e com suas mudanças de objetivos, propósitos e estratégias.

\section{CONCLUSÕES}

Ressalta-se que, no âmbito desta pesquisa, a aprendizagem mostrou-se adequada como lente para analisar os fenômenos organizacionais, válida e relevante porque permitiu não só analisar como as organizações reagiram às mudanças do contexto em que estão inseridas, como também analisar processo, teoria e conteúdo (Easterby-Smith \& Lyles, 2003) da aprendizagem. A reflexão sobre a institucionalização e desinstitucionalização do conhecimento, com base no modelo de Patriotta (2003), possibilitou avançar na compreensão de como determinadas competências são desenvolvidas e suspendidas, atrofiadas e construídas. Os conceitos de competências e aprendizagem organizacional puderam ser integrados e utilizados para compreender o fenômeno em questão e para avançar nos estudos deste campo. Mediante tais conclusões, acredita-se que o objetivo geral da pesquisa de analisar os processos da aprendizagem organizacional ocorridos no desenvolvimento de competências organizacionais em instituições de ensino, a partir da oferta de cursos tecnológicos, foi atingido por meio deste estudo teórico-empírico realizado.

Vale ressaltar que os resultados provenientes desta pesquisa podem trazer contribuições valiosas para as políticas públicas educacionais, para a prática gerencial e para futuras pesquisas na área de aprendizagem organizacional e de educação. Do ponto de vista das políticas públicas de avaliação e controle da oferta dos cursos tecnológicos, observou-se que as instituições de ensino têm respondido e 
se adaptado às novas regulamentações, o que permitiu sua viabilização. No entanto, o estágio em que a educação tecnológica se encontra hoje parece ser crítico, pois pode tanto fluir para a consolidação da aceitação e sua legitimação na sociedade quanto pode perdê-la e diminuir a oferta, caso não haja continuidade, avaliação e aprimoramento das próprias políticas públicas.

Para as instituições de ensino que atuam ou que desejam atuar na modalidade de cursos tecnológicos, o presente trabalho pode contribuir, ressaltando a importância no desenvolvimento de competências relacionadas à seleção e ao treinamento do corpo docente, à interação da instituição com o mercado de trabalho, ao preparo da estrutura física necessária e ao desenvolvimento de metodologias de ensino e avaliação (pedagógicas). No que diz respeito a futuras pesquisas, sugere-se a condução de trabalhos que fortaleçam a relação entre competências e aprendizagem. Recomenda-se o aprofundamento da análise dos processos de institucionalização e "desinstitucionalização" do conhecimento como pré-requisito para a aprendizagem no nível organizacional. Outro aspecto relevante refere-se ao modo como as competências podem ser transferidas entre unidades da mesma instituição. São questões que mereceram atenção e não foram abordadas nos dois estudos de caso, e que somente podem ser analisadas por meio de estudos em profundidade com abordagem longitudinal.

Artigo recebido em 03.04.2009. Aprovado em 15.12.2009.

\section{AGRADECIMENTOS}

Agradecemos à CAPES o apoio financeiro recebido por meio do programa de bolsa no 'Programa de Doutorado no País com Estágio no Exterior’, cuja pesquisa deu origem a este artigo. Agradecemos também aos revisores anônimos desta revista e aos revisores do Encontro Enanpad 2008, onde foi publicada uma versão preliminar deste estudo.

\section{REFERENCIAS BIBLIOGRÁFICAS}

Antonello, C. S. (2005). A metamorfose da aprendizagem organizacional: uma revisão crítica. In R. Ruas, C. S. Antonello, \& L. H. Boff (Orgs.), Aprendizagem organizacional e competencies (pp. 12-33). Porto Alegre: Bookman.

Argyris, C., \& Schön, D. A. (1978). Organizational learning: a theory of action perspective. Workingham: Addison-Wesley.

Bardin, L. (1979). Análise de conteúdo. Lisboa: Edições 70.

Barney, J. (2001). Is the resource-based "view" a useful perspective for strategic management research? Yes. The Academy of Management Review, 26(1), 41-56.

Barney, J., \& Hesserly, W. (1996). Organizational economics: understanding the relationship between organizations and economic analysis. In S. Clegg, C. Hardy, \& W. R. Nord. (Eds.), Handbook of organization studies (pp. 115-147). Longon: Sage Publications.

Barr, P. S., Stimpert, J. L., \& Huff, A. S. (1992). Cognitive change, strategic action, and organizational renewal. Strategic Management Journal, 13(S1), 15-36.

Bitencourt, C. C. (2001). A gestão de competências gerenciais: a contribuição da aprendizagem organizacional. Tese de doutorado, Universidade Federal do Rio Grande do Sul, Porto Alegre, RS, Brasil. 
Cook, S. D. N., \& Yanow, D. (1993). Culture and organizational learning. Journal of Management Inquiry, 2(4), 373-390.

Creswell, J. W. (2002). Research desing: qualitative, quantitative and mixed methods approaches. London: Sage Publications.

Cyert, R. M., \& March, J. G. (1963). A behavioral theory of the firm. New Jersey: Cliffs.

Decreto Federal n. 2208, de 17 de abril de 1997. (1997). Regulamenta parágrafo $2^{\circ}$ do art. 36 e os arts. 39 e 42 da Lei Federal n. 9.394/96. Brasília, DF: Diário Oficial [da] República Federativa do Brasil.

Easterby-Smith, M., \& Lyles, M. A. (2003). Introduction: watersheds of organizational learning and knowledge management. In M. Easterby-Smith \& M. Lyles (Orgs.), The Blackwell Handbook of organizational learning and knowledge management (pp. 1-15). London: Blackwell.

Eisenhardt, K. (1989). Building theories from case study research. Academy of Management Research, 14(4), 532-550.

Fiol, C. M., \& Lyles, M. A. (1985). Organizational learning. The Academy of Management Review, 10(4), 803-813.

Fischer, A. L., \& Silva, N. B. (2004, setembro). Os programas de melhoria contínua como processos de aprendizagem organizacional: o caso de uma indústria de produtos alimentícios. Anais do Encontro Nacional da Associação Nacional de Pós-Graduação e Pesquisa em Administração, Curitiba, PR, Brasil, 28.

Fleury, A. C. C., \& Fleury, M. T. L. (2004). Estratégias empresariais e formação de competências: um quebra cabeça caleidoscópico da indústria brasileira. São Paulo: Atlas.

Guarido Filho, E. R., \& Machado-da-Silva, C. L. (2001). A influência de valores ambientais e organizacionais sobre a aprendizagem organizacional na indústria alimentícia paranaense. Revista de Administração Contemporânea, 5(2), 33-63.

Hedberg, B. (1981). How organizations learn and unlearn. In P. Nystrom \& W. Starbuck. (Orgs.), Handbook of organization design (pp. 3-27). Oxford: Oxford University.

Huber, G. P. (1995). Organizational learning: the contributing processes and the literatures. In M. D. Cohen \& L. S. Sproull (Eds.), Organizational learning (pp. 124-162). London: Sage Publications.

LeBoterf, G. L. (2003). Desenvolvendo a competência dos profissionais. Porto Alegre: Artmed.

Lei $n^{\circ}$ 9.394, de 20 de dezembro de 1996. (1996). Estabelece as diretrizes e bases da educação nacional. Brasília, DF: Diário oficial da União.

Leonard-Barton, D. (1992). Core capabilities and core rigidities: a paradox in managing new product. Strategic Management Journal, 13(S1), 111-125.

Lewis, M. A., \& Gregory, M. J. (1996). Developing and applying a process approach to competence analysis. In R. Sanchez, A. Heene, \& H. Thomas (Eds.), Dynamics of competence-based competition (pp. 141-164). England: Elsevier.

Lyles, M. A., \& Easterby-Smith, M. (2003). Organizational learning and knowledge management: agendas for future research. In M. Easterby-Smith \& M. Lyles (Orgs.), The Blackwell handbook of organizational learning and knowledge management (pp. 639-652). London: Blackwell. 
Machado-da-Silva, C. L., Fonseca, V. S., \& Crubellate, J. M. (2005). Estrutura, agência e interpretação: elementos para uma abordagem recursiva do processo de institucionalização. Revista de Administração Contemporânea, 9(1ª . Edição Especial), 9-39.

March, J. G., \& Olsen, J. P. (1976). Ambiguity and choice in organizations. Bergen: Universitetsforlaget.

Mills, J., Platts, K., Bourne, M., \& Richards, H. (2002). Competing through competences. Cambridge: Cambridge University Press.

Nicolini, D., \& Meznar, M. B. (1995). The social construction of organizational learning: conceptual and pratical issues in the field. Human Relations, 48(7), 727-746.

Nonaka, I., \& Takeuchi, H. (1997). Criação de conhecimento na empresa. Rio de Janeiro: Campus.

Oliver, C. (1992). The antecedents of deinstitutionalization. Organization Studies, 13(4), 563-588.

Patriotta, G. (2003). Organizational knowledge in the making: how firms create, use, and institutionalize knowledge. United States: Oxford University Press.

Portaria n. 646, de 14 de maio de 1997. (1997). Regulamenta a implantação do disposto nos artigos 39 a 42 da Lei no. 2.208/97 e dá outras providências (trata da rede federal de educação tecnológica). Brasília, DF. Recuperado em 04 novembro, 2008, de http://portal.mec.gov.br/setec/arquivos/pdf_legislacao.pdf

Prahalad, C. K., \& Hamel, G. (1990). The core competence of the corporation. Harvard Business Review, 68(3), 79-91.

Prange, C. (2001). Aprendizagem organizacional: desesperadamente em busca de teorias. In M. Easterby-Smith, J. Burgoyne, \& L. Araujo (Orgs.), Aprendizagem organizacional $e$ organizações de aprendizagem: desenvolvimento na teoria e na prática (pp. 41-63). São Paulo: Atlas.

Richardson, R. J. (1989). Pesquisa social: métodos e técnicas. São Paulo: Atlas.

Sanchez, R. (2001). Managing knowledge into competence: the five learning cycles of the competent organization. In R. Sanchez (Org.), Knowledge management and organizational competence (pp. 3-38). Oxford: Oxford University Press.

Sanchez, R., Heene, A., \& Thomas, H. (1996). Dynamics of competence-based competition: theory and practice in the new strategic management. England: Elsevier.

Scott, R. W., \& Meyer, J. W. (1994). Institutional environments and organizations. Thousand Oaks: Sage.

Selltiz, C., Wrightsman, L. S., \& Cook, S. W. (1987). Métodos de pesquisa nas relações sociais. São Paulo: EPU.

Shrivastava, P. (1983). A typology of organizational learning systems. Journal of Management Studies, 20(1), 7-28.

Teece, D. J., Pisano, G., \& Shuen, A. (1997). Dynamic capabilities and strategic management. Strategic Management Journal, 18(7), 509-533.

Triviños, A. N. S. (1987) Introdução à pesquisa em ciências sociais: a pesquisa qualitativa em educação. São Paulo: Atlas. 
Turner, D., \& Crawford, M. (1994). Managing current and future competitive performance: the role of competence. In G. Hamel \& A. Heene (Eds.), Competence-based competition (pp. 241-264). England: John Wiley \& Sons.

Vasconcelos, I. F. G., \& Mascarenhas, A. O. (2007). Organizações em aprendizagem [Coleção Debates em Administração]. São Paulo: Thomson Learning.

Weick, K. E. (1991). The non-traditional quality of organizational learning. Organization Science, 2(1), 116-124.

Weick, K. E., \& Westley, F. (1996). Organizational learning: affirm an oxymoron. In S. Clegg, C. Hardy, \& W. Nord (Eds.), Handbook of organizational studies (pp. 440-458). London: Sage Publications.

Yin, R. K. (2005). Estudo de caso: planejamento e métodos. Porto Alegre: Bookman.

Zarifian, P. (2003). O modelo da competência: trajetória histórica, desafios atuais e propostas. São Paulo: Editora Senac.

Zollo, M., \& Winter, S. G. (2002). Deliberate learning and the evolution of dynamic capabilities. Organization Science, 13(3), 339-351. 